\title{
MAPEAMENTO DA PAISAGEM DA BACIA HIDROGRÁFICA RIO DO CAMPO - CAMPO MOURÃO/PR
}

\author{
${\text { Dener Elivelton } \text { Ciboto }^{(\mathrm{a})} \text {, Ana Paula Colavite }}^{(\mathrm{b})}$ \\ (a) Colegiado de Geografia, Universidade Estadual do Paraná - campus de Campo Mourão, deciboto@ gmail.com \\ (b) Colegiado de Geografia, Universidade Estadual do Paraná - campus de Campo Mourão, apcolavite@ @otmail.com
}

\section{Eixo: GEOTECNOLOGIAS E MODELAGEM ESPACIAL EM GEOGRAFIA FÍSICA}

\begin{abstract}
Resumo
A pesquisa teve foco a elaboração de um banco de dados geográfico da bacia hidrografica do rio do Campo, localizada em Campo Mourão/PR, a partir do qual buscou-se elaborar um conjunto de produtos cartográficos representativos da paisagem local, seus elementos e correlações. A pesquisa se desenvolveu a partir de extensa etapa laboratorial com uso de SIG (Spring) e editor de desenho Corel Draw, com base nos quais foram elaborados os mapas de: Rede Hidrográfica hierarquizada; Hipsometria, Declividade e Orientação das vertentes. Com base nos mapas temáticos constatou-se que a bacia apresenta porte mediano de importância local, com altitude predominante de 600 metros, baixos índices de declividade e orientação das vertentes predominantes em direção noroeste.
\end{abstract}

Palavras chave: Recursos Hídricos, Planejamento da Paisagem, Cartografia Temática.

\section{Introdução}

As bacias hidrográficas constituem sistemas ambientais complexos nos quais interagem variados elementos, tanto do meio físico/natural, quanto resultantes da ação antrópica. Ademais caracterizam-se como um recorte especial de extrema importância ao planejamento e à gestão de um território, especialmente associado à importância dos recursos hídricos para o desenvolvimento da sociedade.

Para Rodrigues e Adami (2005, p. 148) a bacia hidrográfica é considerada um complexo sistema de fluxo de matéria e energia, valendo ressaltar que "não envolvem apenas canais fluviais e planícies de inundação, mas incluem as vertentes, nas quais os processos internos são de fundamental importância”. Nas vertentes, tem-se também o processo de ocupação da terra estabelecido pela sociedade que se manifesta de inúmeras formas e com diversas finalidades, podendo sofrer impactos ambientais com variadas magnitudes, o que interfere diretamente na dinâmica da bacia como um todo.

Com relação à importância de se mapear bacias hidrográfica pode-se citar Landovsky et. al. (2006, p. 189) que expõem "o estudo da paisagem está integrado ao planejamento regional em diversos países sendo, inclusive, fator determinante na implantação ou não de um projeto ou obra de engenharia", para compreender a dinâmica da paisagem é necessário estudar e avaliar inúmeros fatores ambientais (solo, 
hidrografia, geologia, relevo, vegetação, fauna) e também fatores econômico, sociais, culturais e políticos, nesta situação avalia-se o impacto que uma determinada situação geraria nos demais elementos e no contexto do sistema, portanto é ideal para o planejamento e ordenação territorial de uma região.

Diante do exposto objetivou-se, com a presente pesquisa, mapear os elementos da paisagem da bacia hidrográfica do Rio do Campo, localizada em Campo Mourão/PR, especialmente os parâmetros altimétricos e topológicos, bem como a realização de analises espaciais, para desta forma apresentar um breve retrato de seu dinamismo.

\section{Metodologia e Procedimentos}

Segundo Colative $(2009,2010 \mathrm{a}, 2010 \mathrm{~b})$ a referida bacia, apresenta área total de $384 \mathrm{Km}^{2}$, e localiza-se entre as coordenadas $23^{\circ} 53^{\prime}$ e $24^{\circ} 10^{\prime}$ de latitude Sul e $52^{\circ} 15$ e $52^{\circ} 31^{\prime}$ de longitude Oeste, ocupando parte dos municípios de Campo Mourão (aproximadamente 33\% do território municipal) e Peabiru (aproximadamente 30\% do território municipal), conforme representado na figura 01.

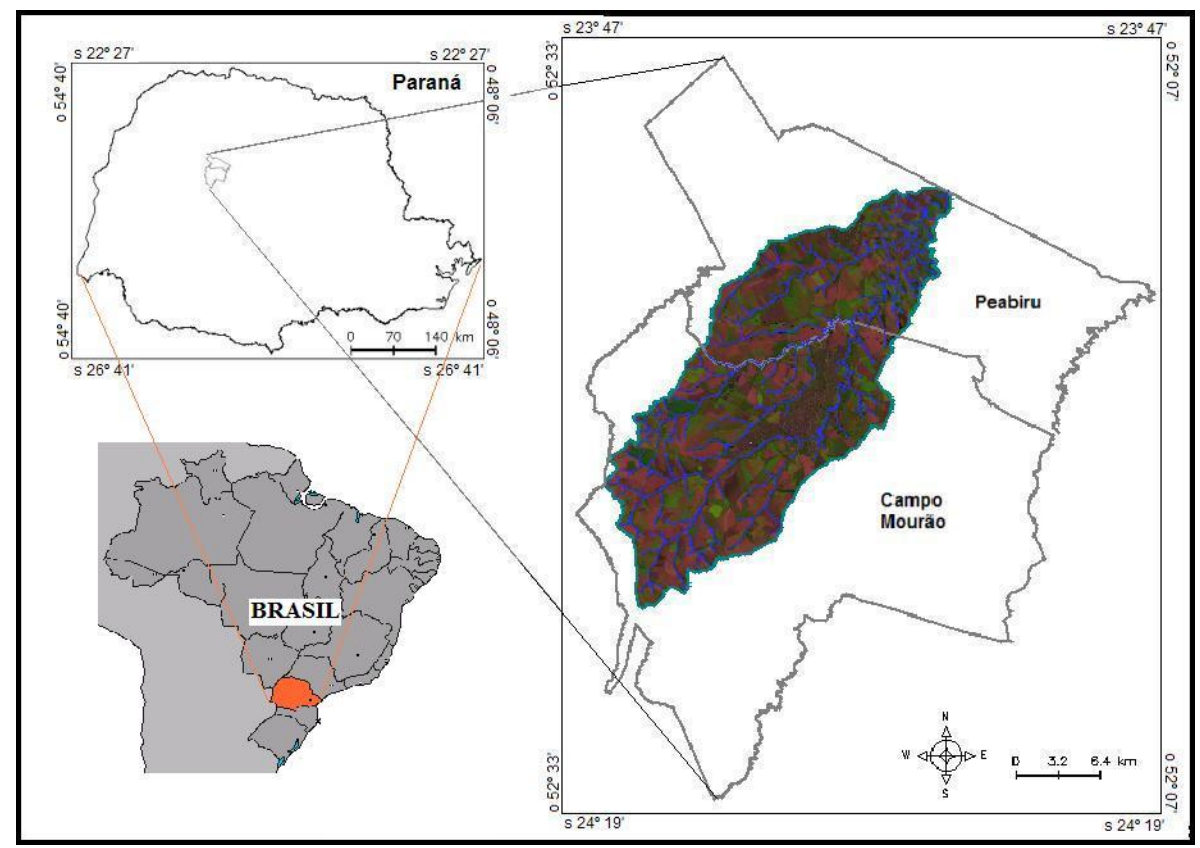

Figura 01: Localização da área de Estudo

Organização: COLAVITE, Ana Paula.

Para a realização, criou-se banco de dados no SPRING 5.1.8 utilizou como base os dados das cartas topográficas de Campo Mourão (folha SG.22-V-B-I-1), Peabiru (folha SF.22-Y-D-IV-3), e Farol (folha SG.22-V-A-III-2) produzidas pelos Ministério do Exército, na escala de 1:50.000, apresentando projeção 
Universal Transversa de Mercator e datum horizontal SAD-69. A partir das cartas topográficas foram extraídos, por edição vetorial, os limites da bacia hidrográfica e a rede de drenagem, a qual foi hierarquizada com base em Strahler (1964). Os canais foram associados às cores diferenciadas variando-se a tonalidade de azul e a espessura da linha para cada uma das ordens, resultando em um mapa de hierarquia dos canais.

Os dados altimétricos foram obtidos a partir do SRTM/Topodata e a correlação de grade com mapas produzidos foi: a partir da grade altimétrica gerou-se o mapa hipsométrico, com faixas de 50 em 50 metros; com base na grade de declive elaborou-se o mapa de declividade com faixas subdivididas de acordo com Silva et al (2003) - 0 a 3\%, 3 a 8\%, 8 a 20\%, 20 a 45\%, 45 a 75\% e maior que 75\%; o mapa de orientação das vertentes foi elaborado a partir da grade de orientação e suas faixas subdividas em 8 classes de acordo com a rosa dos ventos (N, NE, L, SE, S, SO, O, NO).

\section{Resultados e Discussão}

Com base nos mapas temáticos elaborados observou-se que a bacia hidrográfica rio do Campo apresenta ordem final 4 (figura 2A), com formato alongado com orientação de seu curso principal de sudoeste à nordeste. Apresenta 154 canais de ordem 1 (somando $141 \mathrm{Km}$ de comprimento), 37 canais de ordem 2 (somando $79 \mathrm{Km}$ de comprimento), 6 canais de ordem 3 (somando 44Km de comprimento) e o principal de ordem 4 com $54 \mathrm{~km}$ de comprimento.

Com relação à altimetria, com base no mapa hipsométrico (figura 2B), predominam as faixas de 520 à 670 metros, com uma amplitude altimétrica total de 400 metros de desnível. A maior concentração as altas declividades ocorre especialmente no baixo curso da bacia associado às faixas hipsométricas de 370 à 520 metros, local onde são encontradas declividades superiores à $20 \%$ e pequenas áreas enquadradas na faixa de 45 à $75 \%$ (vide figura 2C).

$\mathrm{Na}$ parte central da bacia associado as cotas de altitude predominantes encontram-se baixos indices de inclinação do terreno, especialmente de 0 à $8 \%$ nas altas e médias vertentes, nas baixas vertentes encontram-se terrenos enquadrados na faixa de 8 à $20 \%$ de declividade. Na cabeceira de drenagem (alto curso da bacia) são encontrados medianos indices de declividade associados ao processo de escavação das nascentes.

Com relação à orientação das vertentes (figura 2D) os valores de área obtidos para cada orientação são: a face noroeste é a de maior predominio com $18 \%$ do território; na sequencia a face sudeste apresenta $15 \%$ 


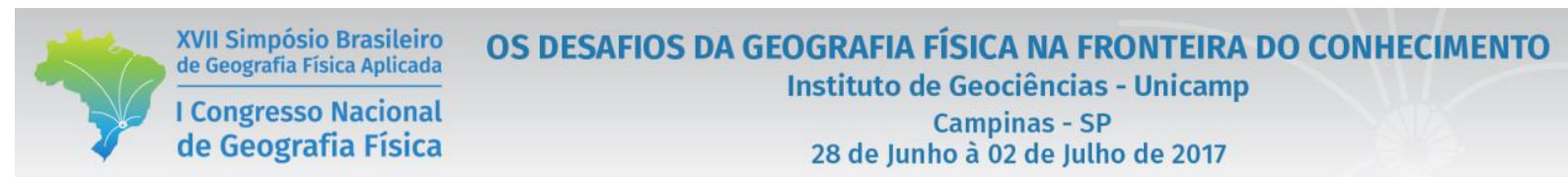

de ocupação territorial cada classe; as faces nordeste, leste e sul ocupam 13\% de área total, cada classe; a face norte ocupa $11 \%$ da área total da bacia; a face oeste $10 \%$ e; a face sudoeste $7 \%$.

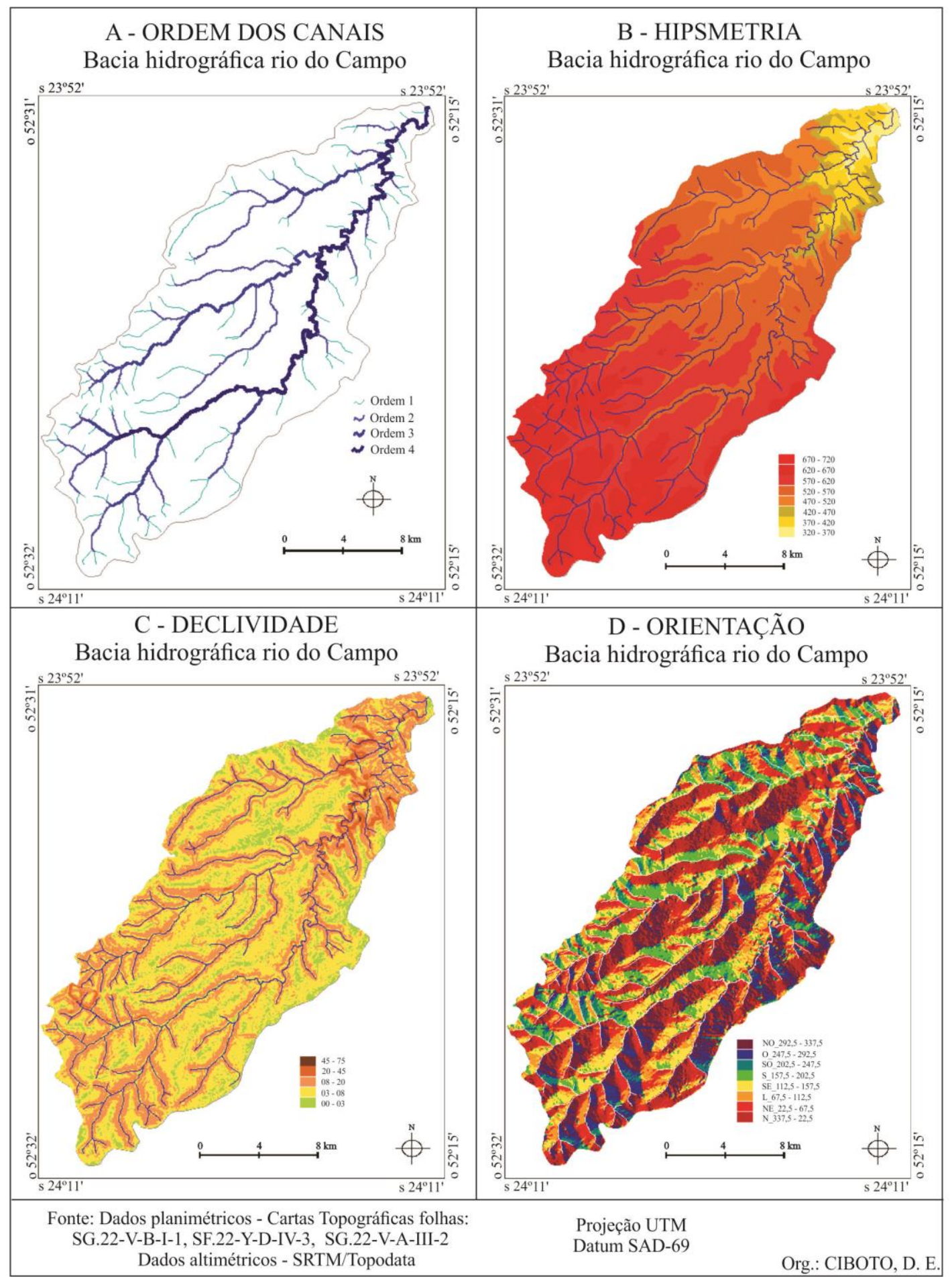

Figura 02: A - mapa Ordem dos Canais; B - mapa Hipsometria; C - mapa Declividade; D - mapa Orientação Organização: CIBOTO, Dener Elivelton. 


\section{Considerações Finais}

A dinamica da paisagem da bacia hidrográfica do rio do Campo apresenta-se diversificada, com diferenciados graus de fragilidade ambiental. A parte do alto curso da bacia apresenta medianos indices de dissecação do terreno, especialmente associados ao processo de escavação das vertentes pelos canais de ordem 1. A parcela do médio curso da bacia é a que apresenta menores indices de declividade e menor amplitude altimétrica, consequentemente a área de menor fragilidade ambiental. O baixo curso da bacia apresenta uma ruptura abrupta do relevo e na sequencia medianos indices de declividade.

Considera-se que no conjunto a bacia hidrográfica apresenta alta aptidão para o uso intensivo da terra, fator este corroborado com a realidade observada in loco, a partir do qual evidencia-se à alta mecanização e baixa diversidade agricola, assim como pequenas parcelas de área preservadas.

\section{Agradecimentos}

Venho por meio deste agradecer a fundação a qual garante fomentos para a pesquisa PIBIC/Fundação Araucária, juntamente com orientadora Dra. Ana Paula Colavite.

\section{Bibliografia}

COLAVITE, A.P. Cartografia aplicada à análise ambiental da bacia hidrográfica do Rio do Campo - PR. 2008. 52f. Monografia (Especialização em Georreferenciamento de Imóveis Urbanos e Rurais) - Universidade Estadual de Maringá, Maringá, 2008.

COLAVITE, Ana Paula . Geotecnologias Aplicadas à Análise Morfométrica da Bacia Hidrográfica do Rio do Campo, Campo Mourão - PR. In: $7^{\circ}$ Congresso Brasileiro de Cartografia Geotécnica e Geoambiental, 2010, Maringá-PR. Anais do $7^{\mathbf{0}}$ Congresso Brasileiro de Cartografia Geotécnica e Geoambiental, $2010 \mathrm{a}$. v. 01.

LANDOVSKY, Geraldo S.; BATISTA, Daniela B.; ARAKI, Hideo. Análise da qualidade visual da paisagem da região de Tibagi, PR, aplicando o sensoriamento remoto. In: Revista Brasileira de Engenharia Agrícola Ambiental. Campina Grande, PB. v.10, n.1, p.188-195, 2006.

RODRIGUES, Cleide; ADAMI, Samuel. Técnicas Fundamentais para o Estudo de Bacias Hidrográficas. In: VETURI, Luis Antonio Bittar (org.). Praticando Geografia: técnicas de campo e laboratório. Oficina de Textos. São Paulo, 2005.

SILVA, A. M. da; SCHUlZ, H. E.; CAMARGO, P. B. de. Erosão e Hidrossedimentologia em Bacias Hidrográficas. Editora RIMA, São Carlos - SP,2003. 


\begin{tabular}{|c|c|}
\hline $\begin{array}{l}\text { XVII Simpósio Brasileiro } \\
\text { de Geografia Fisica Aplicada }\end{array}$ & $\begin{array}{l}\text { OS DESAFIOS DA GEOGRAFIA FÍSICA NA FRONTEIRA DO CONHECIMENTO } \\
\text { Instituto de Geociências - Unicamp }\end{array}$ \\
\hline $\begin{array}{l}\text { I Congresso Nacional } \\
\text { de Geografia Física }\end{array}$ & $\begin{array}{l}\text { Campinas - SP } \\
28 \text { de Junho à } 02 \text { de Julho de } 2017\end{array}$ \\
\hline
\end{tabular}

STRAHLER, Arthur N. Quantitative geomorphology of drainage basins and channel networks. In: CHOW, Ven Te (Ed.). Handbook of applied hydrology: a compendium of water resources technology. New York: Mc-Graw Hill, 1964. 